\title{
Properties of molten $\mathrm{CaCO}_{3}$ at high pressure
}

\section{J. Hudspeth ${ }^{1}$, C. Sanloup ${ }^{1 *}$, Y. Kono ${ }^{2}$}

Abstract

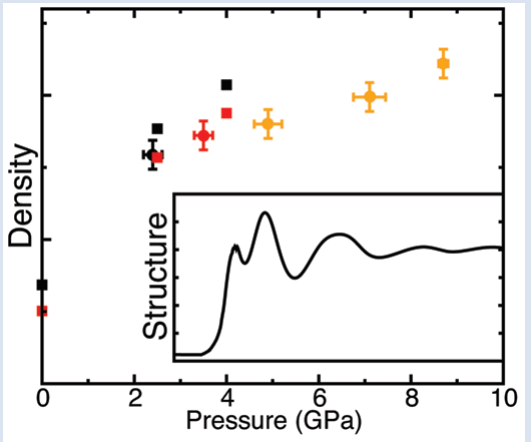

We report here the structure of molten $\mathrm{CaCO}_{3}$ studied by in situ X-ray diffraction using a Paris-Edinburgh press up to $8.7 \mathrm{GPa}$. Variations are observed in the medium range order with shrinkage of the intermolecular contributions, reflecting higher packing efficiency of the carbonate molecules. Density of the melt is obtained from the radial distribution functions, assuming a constant coordination number of 3 for the $\mathrm{C}-\mathrm{O}$ contribution. Bulk modulus values increase by a factor of 2 over the experimental pressure-temperature range, reaching a value similar to that of underlying crystalline phases at the highest pressure investigated. These are the first direct density measurements of compressed $\mathrm{CaCO}_{3}$ melt; they agree well with recent ab initio predictions (Li et al., 2017), which implies that the reported flattening of the melting curve followed by a slightly negative curve above $8 \mathrm{GPa}$ cannot be due to crystal-melt density inversion. Instead, the enthalpy of fusion is likely responsible, and we note the peculiar high diffusivity of oxygen in crystalline calcite- $\mathrm{V}$ in this regard, with further implications for the mobility of carbonate melts at depth.

Received 17 January 2018 | Accepted 5 April 2018 | Published 30 April 2018

\section{Introduction}

The geological importance of carbonate melts is linked to their low melting points compared to silicates, and hence their key role in triggering melting at depth (Jones et al., 2013). As such, the properties of carbonate melts are key in processes ranging from incipient melting at the oceanic lithosphere-asthenosphere boundary and lubrication of tectonic plates (Gaillard et al., 2008), to pervasive metasomatism of the continental lithospheric roots (Foley, 2008).

Experimental measurements of the physical properties of molten carbonates under high pressures $(P)$ are very scarce however. This contrasts with the advances in knowledge on silicate melts under $P$ over the last decade, as reviewed in Kono and Sanloup (2018), and is due to the extreme difficulty in confining such low-viscosity melts for long durations. Structural data at ambient $P$ have been collected on $\mathrm{Li}_{2} \mathrm{CO}_{3}, \mathrm{~K}_{2} \mathrm{CO}_{3}$, $\mathrm{LiKCO}_{3}$ melts using neutron diffraction (Kohara et al., 1998), and $\mathrm{Na}_{2} \mathrm{CO}_{3}$ using X-ray diffraction (Wilding et al., 2016). The effect of $P$ on melt compaction, i.e. the bulk modulus, has been assessed for alkali carbonate melts by combining ambient $P$ density and acoustic velocity measurements (Liu and Lange, 2003), and from the melting curve for $\mathrm{K}_{2} \mathrm{CO}_{3}$ (Liu et al., 2007). In situ high $P$ density measurements are restricted to two $P$ points for molten $\mathrm{K}_{2} \mathrm{Ca}\left(\mathrm{CO}_{3}\right)_{2}\left(2.75 \mathrm{~g} \cdot \mathrm{cm}^{-3}\right.$ at 2.5 GPa-950 ${ }^{\circ} \mathrm{C}, 2.58 \mathrm{~g} \cdot \mathrm{cm}^{-3}$ at $2.5 \mathrm{GPa}-1150{ }^{\circ} \mathrm{C}$, and $2.80 \mathrm{~g} \cdot \mathrm{cm}^{-3}$ at $4 \mathrm{GPa}-1050^{\circ} \mathrm{C}$ ) using the falling sphere technique (Dobson et al., 1996). These first in situ density measurements were complemented by a study of the viscosity of $\mathrm{K}_{2} \mathrm{Ca}\left(\mathrm{CO}_{3}\right)_{2}$ and $\mathrm{K}_{2} \mathrm{Mg}\left(\mathrm{CO}_{3}\right)_{2}$ melts up to $5.5 \mathrm{GPa}$ (Dobson et al., 1996). Such viscosity measurements were very challenging at the time, i.e. before the advent of high speed cameras required to accurately capture rapidly falling spheres. The ultralow viscosity, i.e. two orders of magnitude lower than for molten basalt at $1900 \mathrm{~K}$, was nonetheless confirmed for calcite and dolomite melts (Kono et al., 2014), with no $P$ effect observed up to 6.2 GPa. This latter study also reported the structure of $\mathrm{CaCO}_{3}$ melts but information was restricted to distances greater than $2 \AA$, excluding the $\mathrm{C}-\mathrm{O}$ bond.

In contrast, there are several reported melting curve measurements, as these do not require long experiments and sample integrity can be preserved. Of particular interest is the report of a flattening of the $\mathrm{CaCO}_{3}$ melting curve at $8 \mathrm{GPa}$ followed by a slightly negative slope up to the calcite-aragonite-melt triple point at 13 GPa (Li et al., 2017). This evolution is unique amongst carbonates, with stronger and positive slopes reported for $\mathrm{Na}_{2} \mathrm{CO}_{3}$ and $\mathrm{MgCO}_{3}$ (Li et al., 2017). The flattening of the $\mathrm{CaCO}_{3}$ melting curve was attributed to a density crossover between solid and liquid $\mathrm{CaCO}_{3}$. However, such crossover is only predicted theoretically near $17 \mathrm{GPa}$, and this discrepancy was attributed to approximations in the $a b$ initio calculations, highlighting the need for further experimental measurements of melt density.

We report here structural and density data on molten $\mathrm{CaCO}_{3}$ from in situ X-ray diffraction up to $8.7 \mathrm{GPa}$ and $2073 \mathrm{~K}$, an experimental $P-T$ range that corresponds to upper mantle

1. Sorbonne Université, CNRS-INSU, Institut des Sciences de la Terre de Paris, 75005 Paris, France

2. HPCAT, Geophysical Laboratory, Carnegie Institution of Washington, USA

* Corresponding author (email: chrystele.sanloup@upmc.fr) 
conditions. Attempts to collect data on molten $\mathrm{Na}_{2} \mathrm{CO}_{3}, \mathrm{~K}_{2} \mathrm{CO}_{3}$, and carbonate mixtures failed, and consequently no results are reported here for these compositions. This might indicate that these compositions have even lower viscosities than pure $\mathrm{CaCO}_{3}$ melt, resulting in escape of the molten carbonates from the graphite capsule.

\section{Structural Data}

In situ energy-dispersive X-ray diffraction data were collected under high $P$-T conditions (Table S-1) using a Paris-Edinburgh press. The structure factor, $S(q)$, was derived from the X-ray diffraction patterns (Supplementary Information, SI). The $g(r)$ radial distribution function, a measure of the probability of finding an atom as a function of the radial distance $r$, was obtained by Fourier Transform of the spline smoothened $S(q)$.

$$
g(r)-1 \frac{1}{2 \pi^{2} r n_{0}} \int_{0}^{\infty} q[S(q)-1] \sin (q r) \mathrm{dq},
$$

where $n_{0}=\frac{\rho N_{A}}{M}$ is the atomic density in atoms per $\AA^{3}, \mathrm{~N}_{\mathrm{A}}$ is

Avogadro's constant, $M=100.1 \mathrm{~g} / \mathrm{mol}$ is the mean atomic molar mass of calcite, and $\rho$ its mass density (see below). The first peak in $g(r)$ is the $\mathrm{C}-\mathrm{O}$ intramolecular contribution, which is not expected to change significantly over this $P$-T range. The second peak in $g(r)$ corresponds to the sum of the O-O and $\mathrm{Ca}-\mathrm{O}$ first neighbour contributions at $\sim 2.3 \AA$, and the third peak to the sum of the second $\mathrm{Ca}-\mathrm{O}$ and first $\mathrm{Ca}-\mathrm{Ca}$ contributions $(\sim 4.0 \AA)$. The most pronounced changes in $g(r)$ (Fig. 1b) with $P$ are at $3 \AA$, with an increase of intensity related to the intermolecular $\mathrm{O}-\mathrm{O}$ distance, and the growth of a shoulder around 3.45-3.5 A related to the Ca-Ca intermolecular contribution. These observations are consistent with the shrinkage of interatomic distance, most pronounced for $\mathrm{Ca}-\mathrm{Ca}$ (from $4 \AA$ at ambient $P$ ), and increase in intensity predicted for both contributions by molecular dynamics (MD) calculations (Vuilleumier et al., 2014), as a result of intermolecular packing upon compression. In contrast, intramolecular distances do not change significantly. The intermolecular packing also explains the observed shift of the first sharp diffraction peak in $S(q)$ (Fig. 1a). Concomitantly, MD simulations indicate a gradual increase of the number of carbonate ions around Ca from 6 as in calcite to 9 as in aragonite. It is not possible to estimate the $\mathrm{Ca}-\mathrm{C}$ coordination number from the present data due to the prominence of the major contributions of neighbouring $\mathrm{Ca}-\mathrm{O}$ and $\mathrm{Ca}-\mathrm{Ca}$. However, correspondence between Vuilleumier et al. (2014) MD simulations and our results supports their conclusions, i.e. the $P$-evolution of the liquid structure smoothes out the abrupt changes occurring across the underlying crystalline calcite $\mathrm{V}$-aragonite transition.
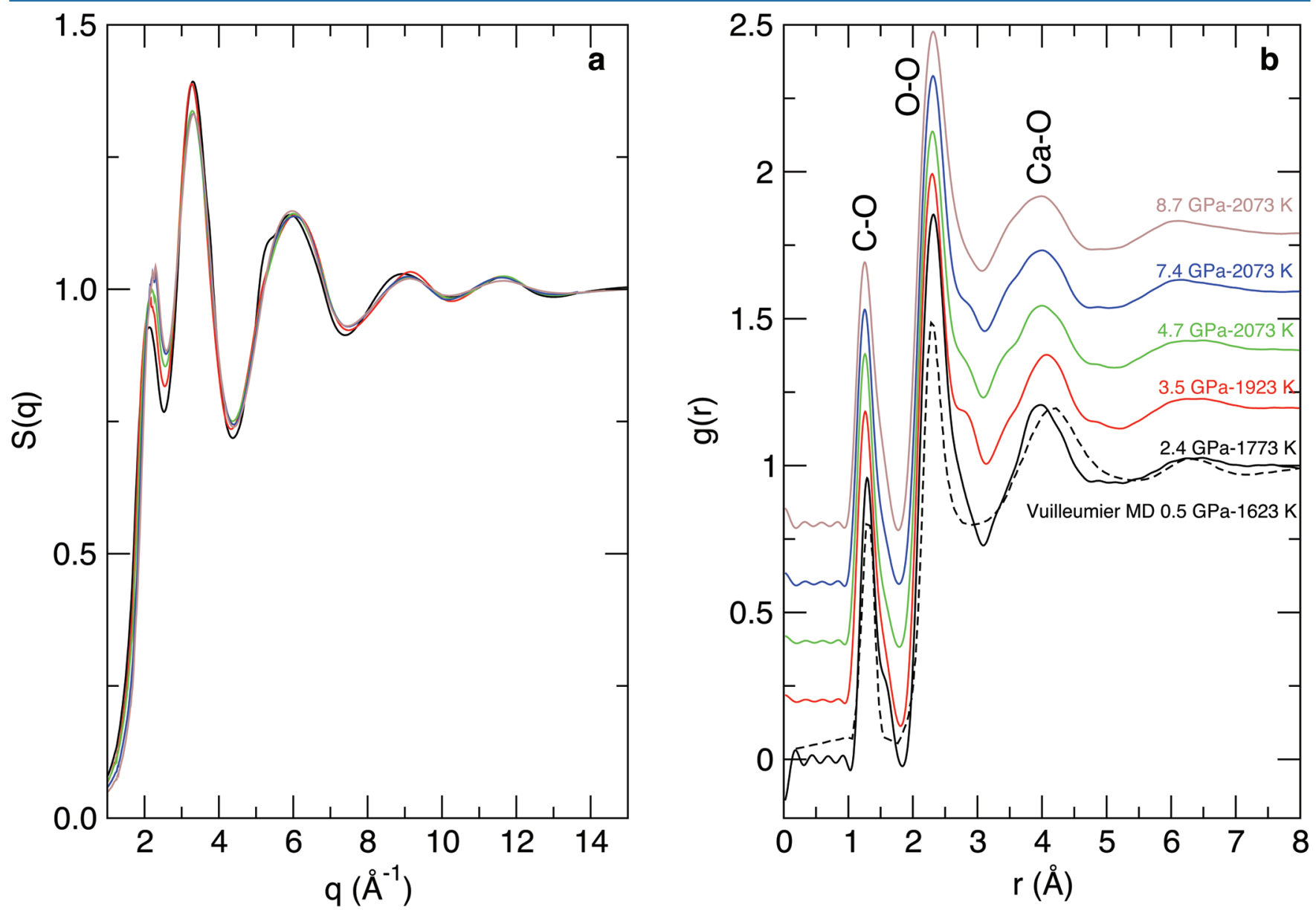

Figure 1 (a) Structure factors, $S(q)$, of molten $\mathrm{CaCO}_{3}$; curves are stacked to see better the evolution with increased $P$ - $T$ conditions (given on the right panel); the main change affecting $S(q)$ (Fig. 1a) is the shift of the first sharp diffraction peak (FSDP) towards higher reciprocal distances, up to $2.28 \AA^{-1}$ at $8.7 \mathrm{GPa}$ which corresponds in the real space to a characteristic mid-range order distance, $2 \pi / q_{F S D P}$ of $2.76 \AA$. (b) Corresponding radial distribution functions (plain curves), $g(r)$, compared to MD simulations (dashed curve; Vuilleumier et al., 2014). 


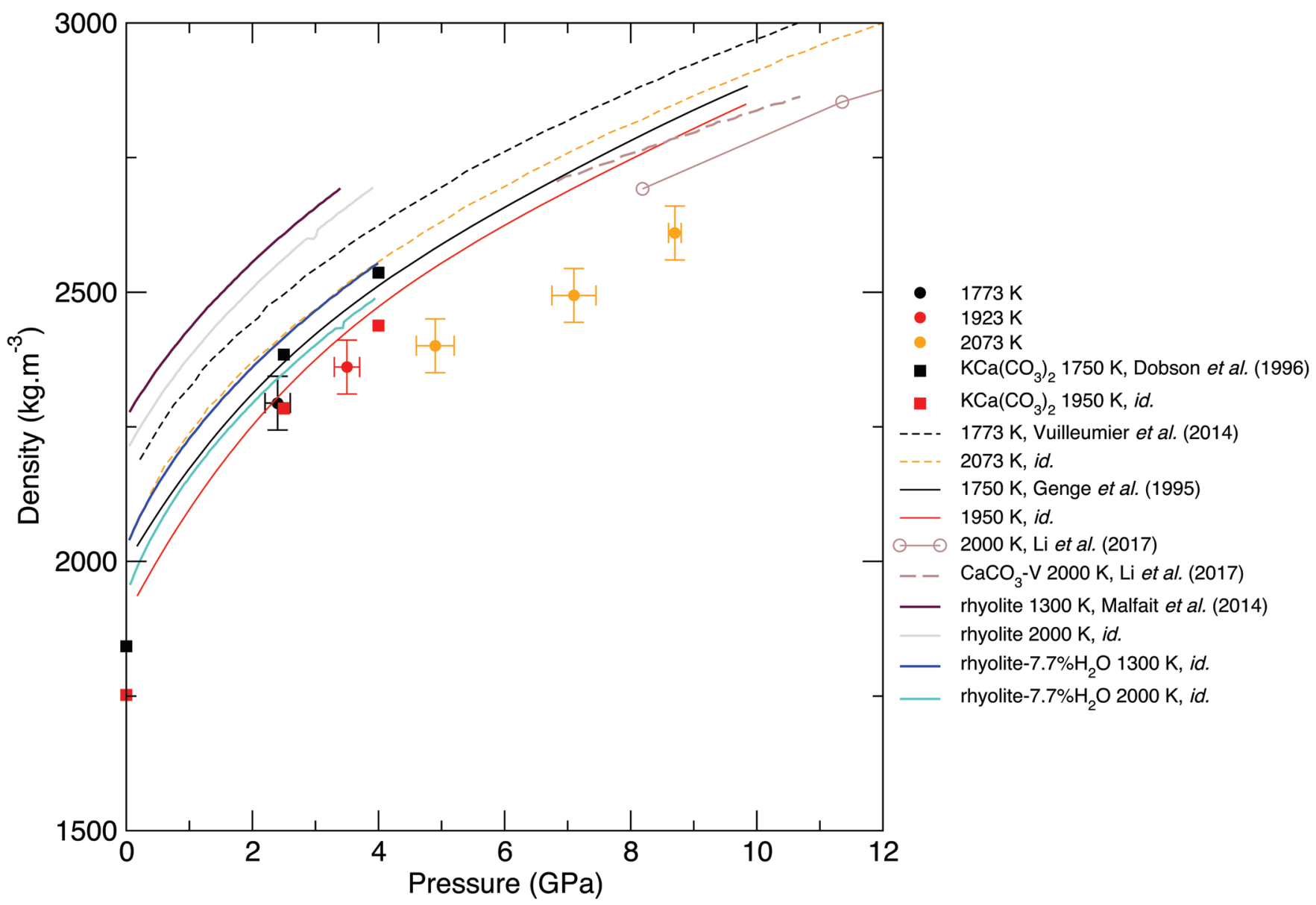

Figure 2 Density of molten $\mathrm{CaCO}_{3}$ from experiments (circles: this work, squares: Dobson et al., 1996) and theoretical calculations (Genge et al., 1995; Vuilleumier et al., 2014; Li et al., 2017), compared to the seismological PREM model (Dziewonski and Anderson, 1981), crystalline calcite V (Li et al., 2017), molten hydrous and dry rhyolite (Malfait et al., 2014), molten hydrous and dry basalt (Sakamaki et al., 2006).

\section{Density Evolution}

The density of $\mathrm{CaCO}_{3}$ melts (Fig. 2) is calculated from the area below the $\mathrm{C}-\mathrm{O}$ contribution to the radial distribution function (Eq. 1 and SI). C is coordinated by three $\mathrm{O}$ in the studied $P$ - $T$ range, but $\mathrm{C}$ becomes tetrahedrally coordinated above 50 GPa in crystalline $\mathrm{MgCO}_{3}$ (Oganov et al., 2008) and above 76 GPa in crystalline $\mathrm{CaCO}_{3}$ (Pickard and Needs, 2015). How this 3 -fold to 4 -fold transition translates at very high $P$ in the molten state remains to be investigated. The calculated density values are consistent with MD simulations by Genge et al. (1995), although the mismatch with more recent simulations (Vuilleumier et al., 2014) is larger, but seems to be in agreement with ab initio calculations from Li et al. (2017).

It is difficult to determine the isothermal bulk modulus, $K_{T}$, by fitting an equation of state to only three data points on the $2073 \mathrm{~K}$ isotherm. An alternative method to assess $K_{T}$ (Egelstaff, 1994) is by extrapolating $S(q)$ to $q=0 \AA^{-1}$ (Fig. S-2

and SI) as $\lim _{q \rightarrow 0} S(q)=\frac{n T k_{B}}{K_{T}}$, where $k_{B}$ is Boltzmann's constant.

This method has been previously benchmarked for molten fayalite using the same experimental set up (Sanloup et al., 2013). Resulting $K_{T}$ values are provided on Figure 3, along with a correction of the two lowest $P$ points to the $2073 \mathrm{~K}$ isotherm using $d K_{T} / d T=0.02 \mathrm{~K}^{-1}$ from Genge et al. (1995). At $8.7 \mathrm{GPa}$, the bulk modulus $(80.6 \pm 3.5 \mathrm{GPa})$ is identical to that of crystalline aragonite (79.5-81.3 GPa) using $K_{T, 0}, K^{\prime}$ and $d K_{T} / d T$ values provided in Litasov et al. (2017), and although no high $T$ data are available for calcite $\mathrm{V}, K_{T, 0}, K^{\prime}$ for aragonite is similar to that of calcite I (Redfern and Angel, 1999). Compared to silicate melts (Fig. 2), molten $\mathrm{CaCO}_{3}$ is less compressible than basalt (Sakamaki et al., 2006) especially at high $P$, but is only approximately $5 \%$ less dense than hydrous rhyolite (Malfait et al., 2014), with a similar $P$-evolution (although the latter has only been investigated up to $4 \mathrm{GPa}$ ).

\section{Discussion}

Our results confirm the liquid density of $\mathrm{CaCO}_{3}$ estimated from ab initio calculations (Li et al., 2017). There is no experimental data on the thermal equation of state of calcite $\mathrm{V}$ due to its very limited T-stability field $(<200 \mathrm{~K})$ and strong recrystallisation processes at high $T$ (Suito et al., 2001), but the good agreement between experimental and theoretical estimates of liquid density lends support to theoretical calcite $\mathrm{V}$ equation of state (Li et al., 2017). Density crossover between solid and liquid phases may hence only occur at $17 \mathrm{GPa}$ as predicted (Li et al., 2017). The reason for the flattening of melting curve around $8 \mathrm{GPa}$, followed by a slightly negative slope up to the calcite $\mathrm{V}$-aragonite-liquid triple point, may consequently be related to changes in the fusion enthalpy rather than a density crossover. Calcite V has a very peculiar molecular structure, with the oxygen sublattice being molten and the oxygen atoms diffusing along an undulated circular orbit (Ishizawa et al., 2013). Such high diffusion of oxygen in crystalline $\mathrm{CaCO}_{3}$ phases is unique to calcite, and in particular, it does not occur 


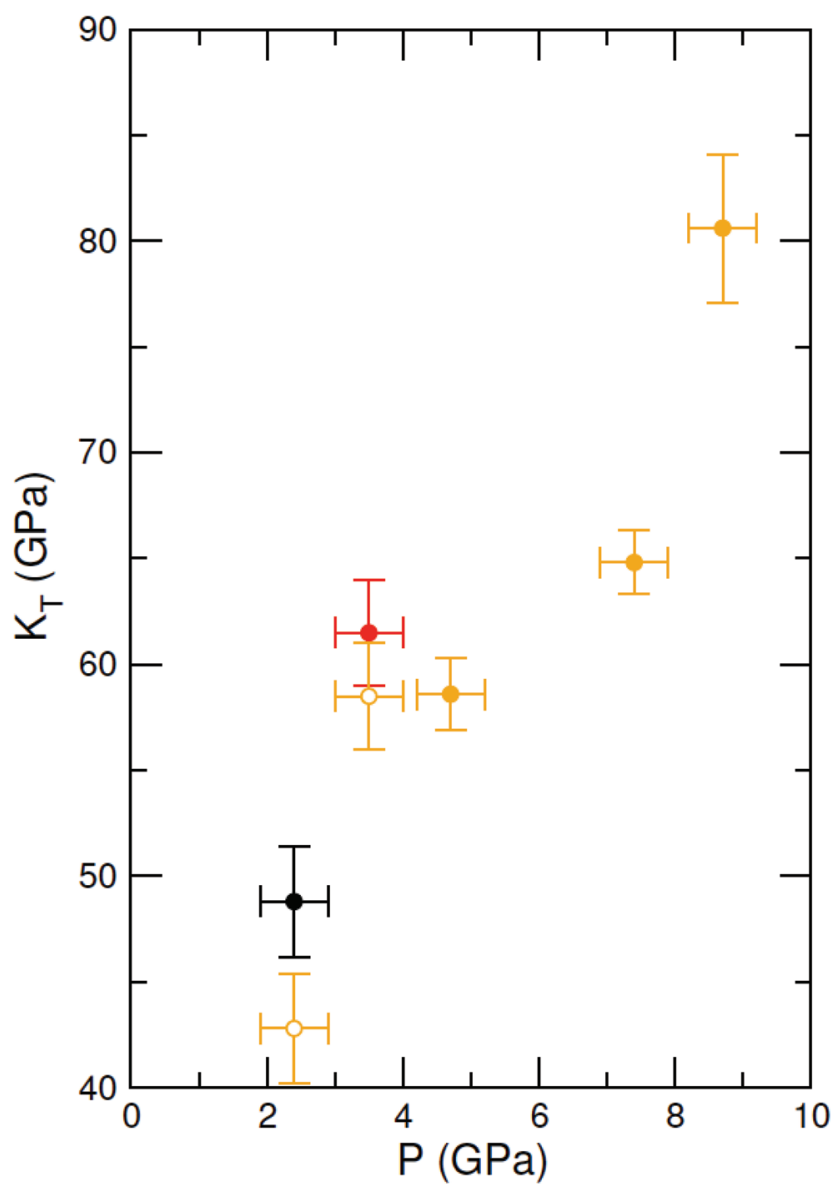

Figure 3 Bulk modulus of molten $\mathrm{CaCO}_{3}$ as a function of $P$ (black: $1773 \mathrm{~K}$, red: $1923 \mathrm{~K}$, orange: $2073 \mathrm{~K}$, orange empty circles: $1773 \mathrm{~K}$ and $1923 \mathrm{~K}$ data corrected for $T=2073 \mathrm{~K}$ ).

in aragonite. Although it is not possible to probe this by X-ray diffraction, it is expected that the change of oxygen mobility also occurs in the molten state from calcite-like at low $P$ to aragonite-like at high $P$. It appears this does not affect the viscosity of the melt vs. $P$ (Kono et al., 2014), as the latter is controlled by the diffusivity of the cations. Due to the gradual nature of the structural changes in the molten state, this highly diffusive state will decrease in the melt at lower $P$ than it does in the crystalline state. Enhanced diffusive motion of oxygen in calcite $\mathrm{V}$ is consequently expected to cause a large enthalpy decrease upon melting into an aragonite-like high $P$ liquid. Similarly, a strong increase of the melting enthalpy $\Delta H$ (i.e. $T \triangle S$ ) of water has been measured above $15 \mathrm{GPa}$ and up to the ice VII-superionic ice $X$ transition, associated with enhanced diffusion of $\mathrm{H}$ atoms in the liquid (Goncharov et al., 2009).

The unique feature of the melting curve of $\mathrm{CaCO}_{3}$ amongst carbonates therefore seems related to the particularity of calcite $\mathrm{V}$. The existence of a $P$ range with negative melting curve related to variation in fusion enthalpy implies that adding heat to the system will freeze it. Corresponding geodynamical settings could be slab-derived melts entrained in upward plumes rising from the transition zone, as proposed for the generation of deep diamonds (Bulanova et al., 2010). Deep carbonate melts cannot indeed derive from melting in the peridotite $+\mathrm{CO}_{2}$ system but from subducted carbonaceous sediments or from metasomatised eclogites (Hammouda and Keshav, 2015), keeping in mind that carbonatitic melts produced above $15 \mathrm{GPa}$ get $\mathrm{Mg}$-enriched while $\mathrm{Ca}$-rich melts $(\mathrm{Ca} \#=0.68-0.70)$ are reported in the 8-14 GPa range (Thomson et al., 2016), coincidental to the negative $\mathrm{CaCO}_{3}$ melting slope. The nature of deep diamond inclusions also points to the presence of Ca-rich protoliths or calcic melts at depths exceeding 300-350 km (Korsakov and Hermann, 2006; Bulanova et al., 2010). Freezing of melts entrained in a plume might then explain the complex, broken and heavily deformed shapes of deep diamonds, indicating formation in a very viscous environment.

Density and structural data are yet to be collected on other carbonate melts, including alkali compositions, in order to assess the properties of all natural compositions. This will require using faster density/structural probes, due to the challenge of confining such inviscid and highly reactive melts under pressure.

\section{Acknowledgements}

We acknowledge funding from the European Community's Seventh Framework Programme (FP7/2007-2013) under grant agreements no. 312284 and 259649 (European Research Council starting grant to C.S.). High pressure experiments were performed at HPCAT (Sector 16), Advanced Photon Source (APS), Argonne National Laboratory. HPCAT operation is supported by DOE-NNSA under Award No. DE-NA0001974, with partial instrumentation funding by NSF. The Advanced Photon Source is a U.S. Department of Energy (DOE) Office of Science User Facility operated for the DOE Office of Science by Argonne National Laboratory under Contract No. DE-AC0206CH11357. Y. K. acknowledges the support of DOE-BES/ DMSE under Award DE-FG02-99ER45775 and support by the National Science Foundation under Award No. EAR-1722495. We acknowledge O. Boudouma for help with SEM analysis, and C. Kenney-Benson for providing cell-assembly parts. We thank an anonymous reviewer and T. Hammouda for thoughtful reviews of the manuscript.

\section{Editor: Simon Redfern}

\section{Additional Information}

Supplementary Information accompanies this letter at http:// www.geochemicalperspectivesletters.org/article1813.

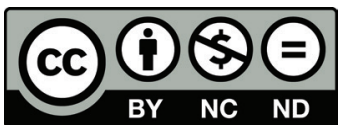

This work is distributed under the Creative Commons Attribution Non-Commercial No-Derivatives 4.0 License, which permits unrestricted distribution provided the original author and source are credited. The material may not be adapted (remixed, transformed or built upon) or used for commercial purposes without written permission from the author. Additional information is available at http://www.geochemicalperspectivesletters.org/ copyright-and-permissions.

Cite this letter as: Hudspeth, J., Sanloup, C., Kono, Y. (2018) Properties of molten $\mathrm{CaCO}_{3}$ at high pressure. Geochem. Persp. Let. 7, 17-21.

\section{References}

Bulanova, G.P., Walter, M.J., Smith, C.B., Kohn, S.C., Armstrong, L.S., BLundy, J., GoBbO, L. (2010) Mineral inclusions in sublithospheric diamonds from Collier 4 kimberlite pipe, Juina, Brazil: subducted protoliths, carbonated melts and primary kimberlite magmatism. Contributions to Mineralogy and Petrology 160, 489-510.

Dobson, D.P., Jones, A.P., Rabe, R., Sekine, T., Kurita, K., Taniguchi, T., Kondo, T., Kato, T., Shimomura, O., Urakawa, S. (1996) In-situ measurement of viscosity and density of carbonate melts at high pressure. Earth and Planetary Science Letters 143, 207-215. 
DzieWOnski, A.M., Anderson, D.L. (1981) Preliminary reference Earth model. Physics of the Earth and Planetary Interiors 25, 297-356.

Egelstaff, P.A. (1994) An Introduction to the Liquid State. Oxford University Press, Oxford.

FolEY, S.F. (2008) Rejuvenation and erosion of the cratonic lithosphere. Nature Geoscience 1, 503-510.

Gaillard, F., Malki, M., Iacono-Marziano, G., Pichavant, M., SCAILLET, B. (2008) Carbonatite melts and electrical conductivity in the asthenosphere. Science 322, 1363-1365.

Genge, M.J., Price, G.D., Jones, A.P. (1995) Molecular dynamics simulations of $\mathrm{CaCO} 3$ melts to mantle pressures and temperatures: implications for carbonatite magmas. Earth and Planetary Science Letters 131, 225-238.

Goncharov, A.F., Sanloup, C., Goldman, N., Crowhurst, J.C., Bastea, S., Howard, W.M., Fried, L. E., Guignot, N., Mezouar, M., MenG, Y. (2009) Dissociative melting of ice VII at high pressure. Journal of Chemical Physics 130, 124514.

Hammouda, T., Keshav, S. (2015) Melting in the mantle in the presence of carbon: Review of experiments and discussion on the origin of carbonatites. Chemical Geology 418, 171-188.

IshizAWA, N., SETOGUCHI, H., YANAGISAWA, K. (2013) Structural evolution of calcite at high temperatures: Phase V unveiled. Scientific Reports 3, 2832

Jones, A.G., Genge, M., CARmody, L. (2013) Carbonate melts and carbonatites. Reviews in Mineralogy and Geochemistry 75, 289-322.

Kohara, S., Badyal, Y.S., Kouray, N., IDemotoy, Y., TAKahashi, S., Curtiss, L.A., SAboungI, M.-L. (1998) The structure of molten alkali carbonates studied by neutron diffraction and ab initio calculations. Journal of Physics: Condensed Matter 10, 3301-3308.

KonO, Y., SANLOUP, C. (2018) Magmas under Pressure: Advances in High-Pressure Experiments on Structure and Properties of Melts. Elsevier, Amsterdam, The Netherlands.

Kono, Y., PArk, C., Kenney-Benson, C., Shen, G., Wang, Y. (2014) Toward comprehensive studies of liquids at high pressures and high temperatures: Combined structure, elastic wave velocity, and viscosity measurements in the Paris-Edinburgh cell. Physics of the Earth and Planetary Interiors 228, 269-280.

KorSAKOV, A.K., HermanN, J. (2006) Silicate and carbonate melt inclusions associated with diamonds in deeply subducted carbonate rocks. Earth and Planetary Science Letters 241, 104-118.

Li, Z., Li, J., Lange, R., LiU, J., Militzer, B. (2017) Determination of calcium carbonate and sodium carbonate melting curves up to Earth's transition zone pressures with implications for the deep carbon cycle. Earth and Planetary Science Letters 457, 395-402.

Litasov, K.D., Shatskiy, A., Gavryushkin, P.N., Bekhtenova, A.E., Dorogokupets, P.I., DAnilov, B.S., Higo, Y., AKilbekov, A.T., INERBAEV, T.M. (2017) P-V-T equation of state of $\mathrm{CaCO}_{3}$ aragonite to $29 \mathrm{GPa}$ and $1673 \mathrm{~K}$ : In situ X-ray diffraction study. Physics of the Earth and Planetary Interiors 2654, 82-91.

LIU, Q., LANGE, R.A. (2003) New density measurements on carbonate liquids and the partial molar volume of the $\mathrm{CaCO}_{3}$ component. Contributions to Mineralogy and Petrology 146, 370-381.

LiU, Q., Tenner, T.J., LAnge, R.A. (2007) Do carbonate liquids become denser than silicate liquids at pressure? Constraints from the fusion curve of $\mathrm{K}_{2} \mathrm{CO}_{3}$ to $3.2 \mathrm{GPa}$. Contributions to Mineralogy and Petrology 153, 55-66.

Malfait, W.J., Seifert, R., Petitgirard, S., Perrillat, J.-P., Mezouar, M., Ota, T., Nakamura, E., Lerch, P., SAnchez-VAlle, C. (2014) Supervolcano eruptions driven by melt buoyancy in large silicic magma chambers. Nature Geoscience 7, 122-125.

OganOV, A.R., ONO, S., MA, Y., GLASS, C.W., GARCIA, A. (2008) Novel high pressure structures of $\mathrm{MgCO}_{3}, \mathrm{CaCO}_{3}$ and $\mathrm{CO}_{2}$ and their role in Earth's lower mantle. Earth and Planetary Science Letters 273, 38-47.

Pickard, C.J., NeEDS, R.J. (2015) Structures and stability of calcium and magnesium carbonates at mantle pressures. Physical Review B 91, 104101.

Redfern, S.A.T., ANGEL, R.J. (1999) High-pressure behaviour and equation of state of calcite, $\mathrm{CaCO}_{3}$. Contributions to Mineralogy and Petrology 134, 102-106.

SAKAMAKI, T., SuzukI, A., OHTAnI, E. (2006) Stability of hydrous melt at the base of the Earth's upper mantle. Nature 439, 192-194.

Sanloup, C., Drewitt, J.W.E., Cr'episson, C., Kono, Y., Park, C., McCammon, C., Hennet, L., Brassamin, S., BYtchkov, A. (2013) Structure and density of molten fayalite at high pressure. Geochimica et Cosmochimica Acta 118, 118-128.
Suito, K., Namba, J., Horikawa, T., Taniguchi, Y., Sakurai, N., Kobayashi, M., Onodera, A., Shimomura, O., Kikegawa, T. (2001) Phase relations of $\mathrm{CaCO}_{3}$ at high pressure and high temperature. American Mineralogist 86, 997-1002.

Thomson, A.R., Walter, M.J., Kohn, S.C., BroOKer, R.A. (2016) Slab melting as a barrier to deep carbon subduction. Nature 529, 76-79.

Vuilleumier, R., Seitsonen, A., Sator, N., Guillot, B. (2014) Structure, equation of state and transport properties of molten calcium carbonate $\left(\mathrm{CaCO}_{3}\right)$ by atomistic simulations. Geochimica et Cosmochimica Acta 141, 547-566.

Wilding, M.C., Wilson, M., Alderman, O.L.G., Benmore, C., Weber, J.K.R., PARISE, J.B., TAmalonis, A., Skinner, L. (2016) Low-dimensional network formation in molten sodium carbonate. Scientific Reports 6, 24415 